PRE-PRINT (initial submitted article).

Accepted version (Elsevier, DRM2020): https://doi.org/10.1016/j.diamond.2020.108154

\title{
Diamond semiconductor performances in power electronics applications.
}

Gaëtan Perez ${ }^{1), 2)}$, Aurélien Maréchal ${ }^{1)}$, Gauthier Chicot $^{3)}$, Pierre Lefranc ${ }^{4)}$, Pierre-Olivier Jeannin ${ }^{4)}$, David Eon ${ }^{5}$, Nicolas Rouger ${ }^{6}$

${ }^{1)}$ At the time of this work: Univ. Grenoble Alpes, CNRS, Grenoble INP*, G2Elab, 38000 Grenoble, France

${ }^{2)}$ Currently: CEA Liten

3)Diamfab

4)Univ. Grenoble Alpes, CNRS, Grenoble INP*, G2Elab, 38000 Grenoble, France

5)Université Grenoble Alpes, CNRS, Institut Néel, F-38042 Grenoble, France

6)Université de Toulouse ; LAPLACE ; CNRS ; INPT ; UPS, F-31071 Toulouse, France

Abstract: This paper proposes a system-level comparison between diamond and SiC power devices. It highlights the benefits of diamond semiconductors for power electronics applications. Actual diamond power devices are fabricated and characterized (DC, AC small-signal and largesignal power switching in a buck converter). Thanks to the experimental data, the models of diamond devices are discussed and the expected performances of future diamond semiconductors in power converters are presented. These performances are compared to the commercialized SiC Schottky diodes for a given application. Our analysis shows that diamond devices can be used to increase power converters' performances especially at high temperature. It is demonstrated that for a $450 \mathrm{~K}$ junction temperature diamond semiconductors can divide by three the semiconductor losses and heatsink volume in comparison to SiC devices. We also demonstrate that the switching frequency with diamond devices can be five times higher than with SiC devices, with lower total semiconductor losses and smaller heatsink in diamond based power converters. This system level analysis clearly shows the future improvements of power converters' efficiency and their power densities thanks to diamond power devices. The need of a 
PRE-PRINT (initial submitted article).

Accepted version (Elsevier, DRM2020): https://doi.org/10.1016/j.diamond.2020.108154

specific junction temperature management, required to use the entire benefits of diamond properties, is finally demonstrated and discussed.

Keywords: Diamond, Wide Bandgap, semiconductors, self-heating effect, semiconductor losses, heatsink volume, performance comparison.

\section{INTRODUCTION AND REVIEW OF DIAMOND POWER DEVICES}

Wide bandgap (WBG) semiconductors have been used since several years to improve performances of power electronics converters. Materials such as silicon carbide (SiC) or gallium nitride (GaN) allow power converters to operate at higher voltages, higher temperatures, and higher switching frequencies than silicon (Si) [1]. These benefits are offered by the superiorities of the WBG materials[2], [3]. Among WBG semiconductors, diamond is the most promising material for power electronics applications. Whereas experimental benefits of SiC and GaN devices in actual power converters have been widely demonstrated, the system level benefits of diamond power devices have not been yet clearly described. This article will offer a system level benchmark of diamond devices in power converters, based on the characteristics of fabricated diamond Schottky diodes, their implementation in power converters and a theoretical benchmark versus SiC power devices. The physical properties of diamond such as a high electric field (10 $\mathrm{MV} / \mathrm{cm})$, a high hole mobility $\left(1300 \mathrm{~cm}^{2} /(\mathrm{V} . \mathrm{s})\right)$ [4] make it the most suitable semiconductor for high power converters. These values are calculated at room temperature for a $1 \mathrm{kV}$ breakdown voltage with a $1.6 \times 10^{17} \mathrm{~cm}^{-3}$ doping level for the required drift region. These properties combined with a high thermal conductivity $(22 \mathrm{~W} /(\mathrm{cm} . \mathrm{K}))$ and a very low intrinsic carrier concentration at 
PRE-PRINT (initial submitted article).

Accepted version (Elsevier, DRM2020): https://doi.org/10.1016/j.diamond.2020.108154

room temperature $\left(2.2 \times 10^{-27} \mathrm{~cm}^{-3}\right)$ lead to the highest figures of merit (FOM) [2], higher than $\mathrm{SiC}$ or GaN materials.

One of the most specific property of bulk diamond semiconductors is the incomplete ionization of boron ( $p$-type layers) and phosphorus dopants ( $n$-type layers) at room temperature, these dopants are then activated by increasing the junction temperature. Other devices based on a two dimensional hole gas (2DHG) in Hydrogen-terminated diamond have been also presented [5], where a large sheet carrier density is available even at low temperatures. In our analysis, we will further consider only bulk Chemical Vapor Deposition (CVD) grown diamond devices, since 2DHG-based diamond devices are still subject to instabilities and reliability issues [6], albeit with already attractive performances for power electronics [7]. Concerning the carrier mobility in CVD diamond, both electron and hole mobilities are reduced at higher temperatures [8], [9]. As the device on-state resistance is impacted by the carrier concentration and their mobility, the two opposite evolutions of incomplete ionization and mobility lead to, first a negative temperature coefficient (NTC) and then a positive temperature coefficient (PTC) of the diamond device onstate resistance. The on-state resistance is then minimized at a high temperature [10], [11], this temperature being doping (and breakdown voltage) dependent. Such an evolution is shown experimentally in Figure 1, where the measured on-state resistance of a $200 \mu \mathrm{m} \times 200 \mu \mathrm{m}$ pseudovertical diamond Schottky Barrier Diode (SBD), fabricated at Néel Institute (Grenoble, France) is presented. It highlights the NTC of the diode resistance between $300 \mathrm{~K}$ (RT) and $450 \mathrm{~K}$ and a PTC for temperatures higher than $450 \mathrm{~K}$. A picture and a 3D schematic of the device are shown in Figure 2. A $200 \mathrm{~nm} \mathrm{p}$ layer $\left(10^{20} \mathrm{~cm}^{-3}\right)$ is grown on a lb HPHT diamond substrate (Electrically insulating, nitrogen doped, monocrystalline High Pressure High Temperature diamond substrate), 
PRE-PRINT (initial submitted article).

Accepted version (Elsevier, DRM2020): https://doi.org/10.1016/j.diamond.2020.108154

a $2 \mu \mathrm{m} p^{-}$layer $\left(5.10^{15} \mathrm{~cm}^{-3}\right)$ is then grown on the $p^{+}$layer. A ohmic contact $(\mathrm{Ti}(20 \mathrm{~nm}) / \mathrm{Pt}(20 \mathrm{~nm})$ / Au $(10 \mathrm{~nm}))$ is deposited on the $p^{+}$layer, several Schottky contacts $(\mathrm{Zr}(30 \mathrm{~nm}) / \mathrm{Pt}(20 \mathrm{~nm}) / \mathrm{Au}$ $(10 \mathrm{~nm}))$ are deposited at the center of the device on the $p^{-}$layer. The realization process is described in [12]. The diamond die is then composed of several SBD connected with a common anode (Ohmic contact) and electrically isolated cathodes (Schottky contacts).

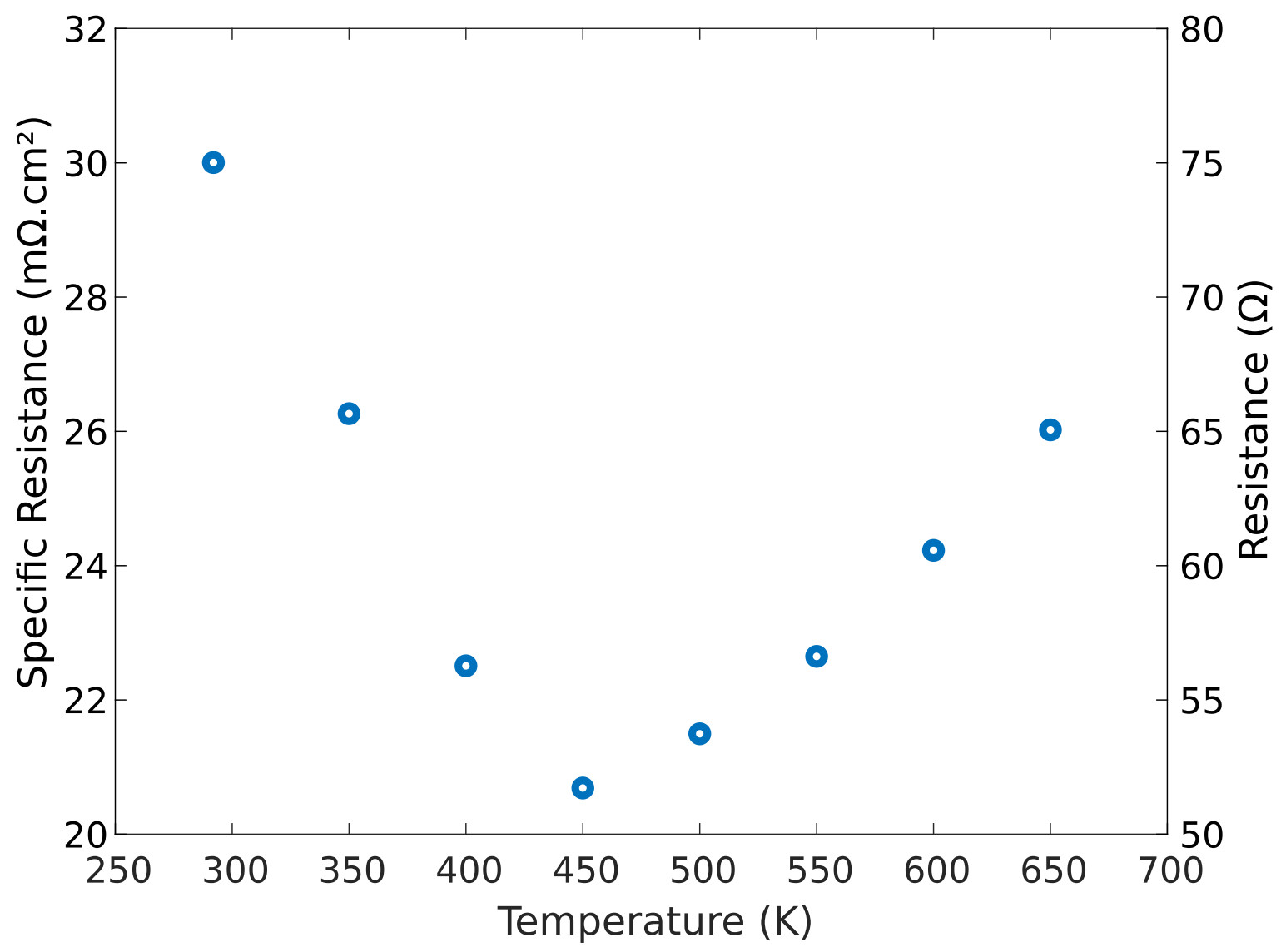

Figure 1: Measured on-state resistance of a $200 \mu \mathrm{m} \times 200 \mu \mathrm{m}$ diamond Schottky Barrier Diode as a function of the junction temperature. 
PRE-PRINT (initial submitted article).

Accepted version (Elsevier, DRM2020): https://doi.org/10.1016/j.diamond.2020.108154

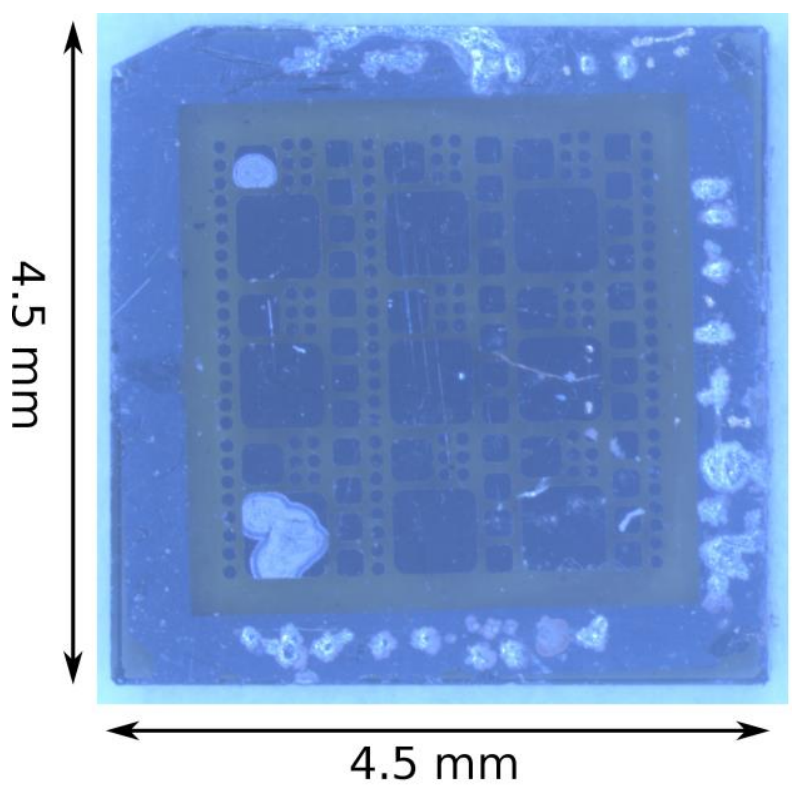

a)

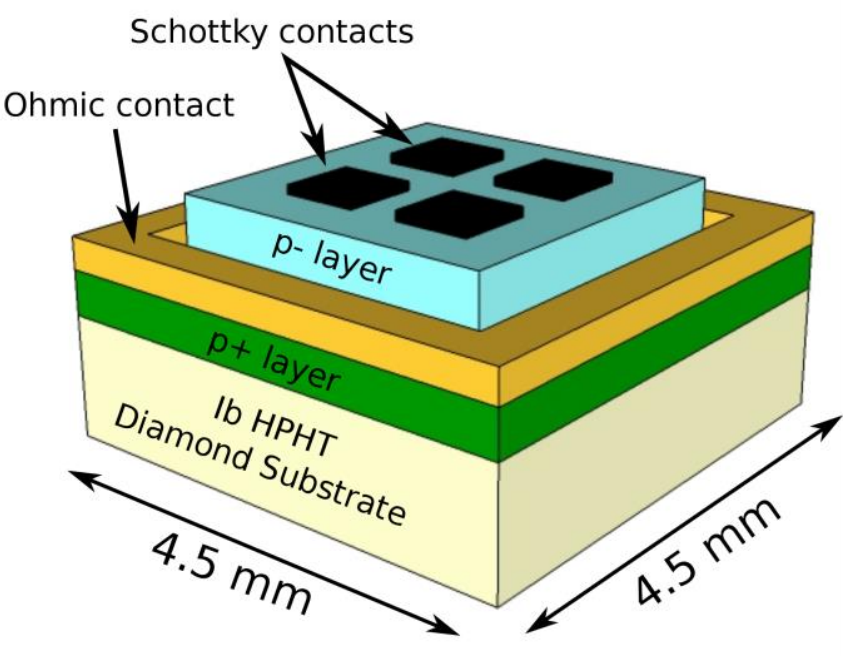

b)

Figure 2: a) Picture of the characterized pseudo-vertical diamond SBD, b) 3D Schematic of the diamond SBD.

Experimental static characteristics of a $200 \mu \mathrm{m} \times 200 \mu \mathrm{m}$ diamond SBD at Room Temperature (RT) are shown in Figure 3. The diode breakdown voltage has not been reached; the reverse characterization has been stopped at $-100 \mathrm{~V}$ due to the high leakage current seen on the reverse characteristic $\left(10^{-4} \mathrm{~A} / \mathrm{cm}^{2}\right)$. Such a high leakage current can be caused by defects in the diamond substrate and the $p$-type layers [13]. Higher breakdown voltages for similar diamond SBD have been experimentally obtained, such as $1 \mathrm{kV}[12]$ and $10 \mathrm{kV}$ with thicker drift regions and a planar SBD structure [14]. Even if diamond physical properties are very promising for power electronics applications, performances of diamond devices are currently lower than the theoretical expected values. Several phenomena can be responsible for these limitations. One of them is a limitation of the breakdown voltage (BV) caused by the electric field crowding at the 
PRE-PRINT (initial submitted article).

Accepted version (Elsevier, DRM2020): https://doi.org/10.1016/j.diamond.2020.108154

edge of the electrodes [15] and the lack of efficient junction termination extension solutions. The avalanche breakdown mechanism appears at the edge of the electrode for lower voltages than designed, the device structure is then responsible for this limitation. Several edge termination techniques are investigated in the literature in order to solve this issue. Benefits of field plates have been shown [16], [17], the use of floating metal guard rings (FMGR) is also demonstrated on diamond Schottky diodes [18]. Even if these improvements are required to reach diamond physical limits in terms of critical electric field, these limitations are not a particularity of diamond semiconductors. Indeed, edge termination techniques have been used for SiC and GaN semiconductors [19], [20]. Apart from off-state improvements of diamond devices, other studies are conducted to optimize the on-state characteristics. An optimization of diamond devices drift layers has been investigated in the way to minimize the drift layer resistance for given breakdown voltages. A trade-off between the doping concentration, the layer thickness and the punch through (PT) factor have been used to optimize the drift layers [21]. 
PRE-PRINT (initial submitted article).

Accepted version (Elsevier, DRM2020): https://doi.org/10.1016/j.diamond.2020.108154

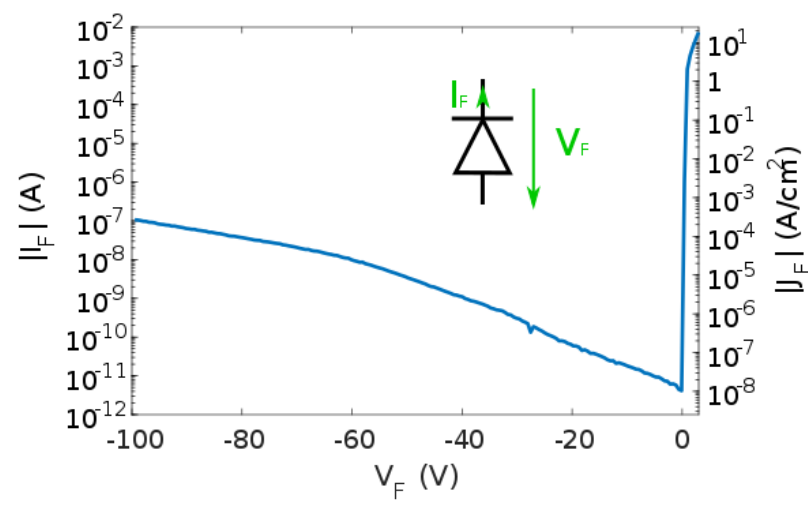

a)

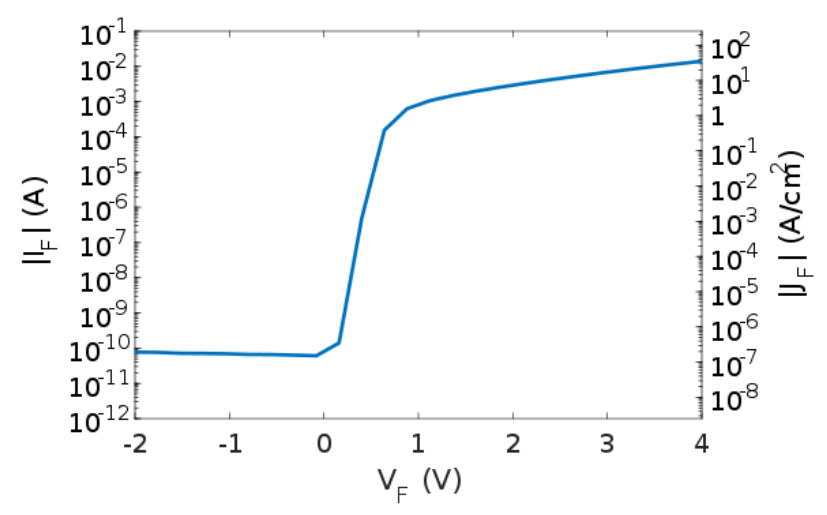

b)

Figure 3: Measured static characteristics of the $200 \mu \mathrm{m} \times 200 \mu \mathrm{m}$ diamond SBD at room temperature. a) Reverse characteristic ( $\mathrm{V}_{\mathrm{F}}$ and $\mathrm{I}_{\mathrm{F}}$ are both negative), b) Forward characteristic ( $\mathrm{V}_{\mathrm{F}}$ and $\mathrm{I}_{\mathrm{F}}$ are both positive).

Even if the actual performances of diamond devices are lower than expected, several diamond device structures have been experimentally demonstrated [22]. Diamond Schottky diodes with high electric field $(7.7 \mathrm{MV} / \mathrm{cm})[14]$, with a high power figure of merit $\left(244 \mathrm{MW} / \mathrm{cm}^{2}\right)$ [12] and with 20 A current rating [23] have been successfully fabricated. Even if $n$-type layers are challenging for diamond, bipolar diodes can be seen in the literature [24] where a $1 \mathrm{kV}$ breakdown voltage has been reached and diamond Schottky PN diodes with better compromises in on-state losses and off-state leakage currents [25]. Concerning transistors, the diamond MESFET (BV = 1.5 kV) [26] and the deep depletion MOSFET (BV $=200 \mathrm{~V}$, breakdown field $=4 \mathrm{MV} / \mathrm{cm}$ ) [27] use the deep depletion regime which is stable thanks to the diamond properties [28]. Diamond transistors using a two dimensional hole gas (2DHG) have also been demonstrated with a $1700 \mathrm{~V}$ breakdown voltage [5]. This emergence of diamond based semiconductor devices shows the necessity to 
PRE-PRINT (initial submitted article).

Accepted version (Elsevier, DRM2020): https://doi.org/10.1016/j.diamond.2020.108154

work in advance on the integration of these devices in power converters. This preliminary study is required to develop power converters adapted to diamond semiconductors physical properties

in the way to use their full potentials. The predicted performances of diamond semiconductors in a power converter are then studied in this paper. The potential of diamond devices in power electronics applications is highlighted and used to define the requirements of power converters based on diamond devices.

\section{METHOD FOR A SYSTEM-LEVEL BENCHMARK}

In order to analyze the benefits allowed by diamond semiconductors in power converters, the performances of diamond semiconductors are compared to those of SiC in the same converter. For this comparison, diamond components characteristics are based on analytical state of the art models, fitted from up to date experimental data. This article is then presenting the expected performances of diamond unipolar devices and it highlights the rules to design power converters due to the particularities of diamond material. The diamond analytical models for both on and off-state parameters are described in [4], [21], where an optimized diamond device drift layer for a given breakdown voltage is considered. These models use the hypothesis of a one dimensional avalanche breakdown based on the impact ionization coefficients proposed in [29]. The drift layer resistance is calculated by using the temperature dependence of the incomplete ionization model [4] and the empirical hole mobility model [30] in CVD diamond. The diamond device characteristics are compared to a SiC commercial off-the-shelf (COTS) power device. As both diamond and SiC semiconductors are dedicated to high voltage, high temperature and fast switching applications [31], it is natural to compare the benefits allowed by diamond 
PRE-PRINT (initial submitted article).

Accepted version (Elsevier, DRM2020): https://doi.org/10.1016/j.diamond.2020.108154

devices to other WBG devices for the same application. In this article, all the comparisons are done by using Schottky diodes. However, this study can be applied to all unipolar semiconductor devices based on a bulk conduction (albeit unipolar devices where the conduction is based on a two dimensional gas are not included in the analysis). Some differences need to be taken into account to accurately specify the performances of each diamond component (Schottky, MOSFET, JFET...). The differences can be either the barrier height for the Schottky diode (conduction losses) or the impact of the gate driver circuit for the diamond MOSFET and JFET (switching losses). All these differences are not considered in this article.

Two parameters are compared in the first analysis, the semiconductor losses and the volume of semiconductors heatsink. These comparisons are performed for different junction temperatures in a $900 \mathrm{~V} / 10 \mathrm{~A}$ buck converter where a transistor is associated to a Schottky diode; a $25 \mathrm{kHz}$ switching frequency $\left(\mathrm{f}_{\mathrm{sw}}\right)$ is used (unless otherwise specified), the duty cycle $(\alpha)$ is considered as $50 \%$ and the ambient temperature is $300 \mathrm{~K}$. A second analysis is then used to include the power converter's switching frequency in the comparison. We assume that the associated transistor and diode are based on the same material and are well designed, their voltage and current ratings are the same. The breakdown voltage of each semiconductor is considered as $1.2 \mathrm{kV}$. The SiC Schottky diode CPW4-1200-S010B (1.2 kV / 10 A) from Wolfspeed corporation is selected for the comparison. For a $1.2 \mathrm{kV}$ breakdown voltage and a Non Punch Through (NPT) design, the diamond Schottky diode drift layer is optimized with a $2.5 \mu \mathrm{m}$ thickness and a $1.2 \times 10^{17} \mathrm{~cm}^{-3}$ Boron doping level [21]. The on-state resistance as a function of the junction temperature of the modeled diamond SBD and the selected SiC Schottky diode are presented in Figure 4. The surface of the diamond SBD has been set to allow the same 
PRE-PRINT (initial submitted article).

Accepted version (Elsevier, DRM2020): https://doi.org/10.1016/j.diamond.2020.108154

conduction losses between the $\mathrm{SiC}$ and the diamond diodes at the temperature, which minimizes the on-state resistance. For an area of $0.37 \mathrm{~mm}^{2}$, the diamond conduction losses at $640 \mathrm{~K}$ are equal to those of the SiC diode at $300 \mathrm{~K}\left(3.92 \mathrm{~mm}^{2}\right.$ area). The negative temperature coefficient (from $300 \mathrm{~K}$ to $640 \mathrm{~K}$ ) and the positive temperature coefficient (higher than 640K) of the diamond SBD on-state resistance is shown. The SiC Schottky diode on-state resistance is extracted from the datasheet at four temperatures, the evolution of its resistance is then estimated in the whole temperature range. It shows the PTC of the SiC diode on-state resistance from $300 \mathrm{~K}$ to higher temperatures. For these two diodes, the thermal resistance of the required heatsink is estimated as a function of the desired operating junction temperature.

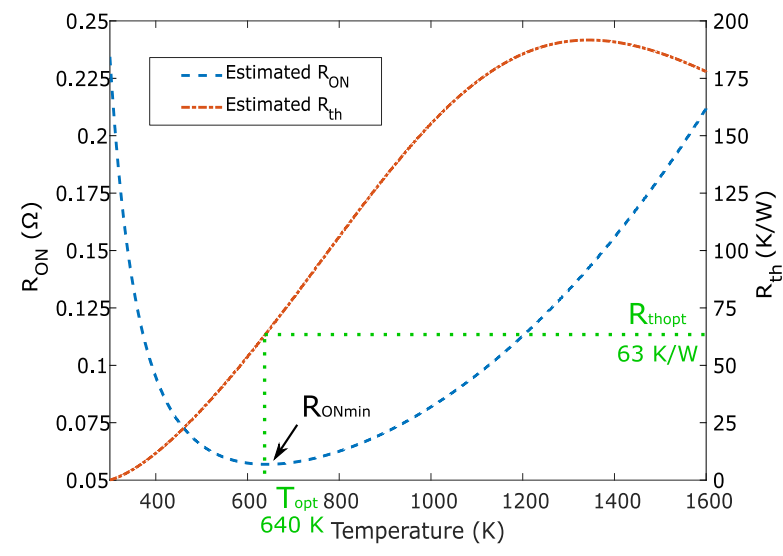

a)

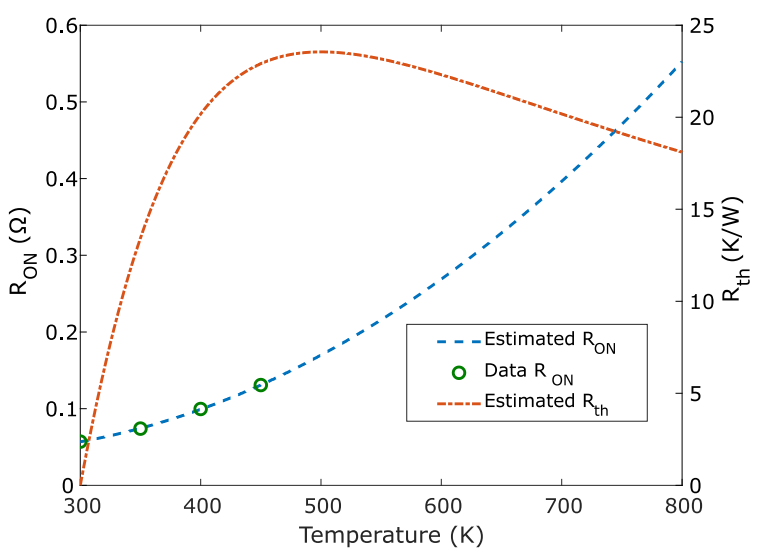

b)

Figure 4: Evolution of the on-state resistance and the estimated thermal resistance of the dedicated heatsink as a function of the temperature for a) the diamond SBD, b) the SiC Schottky diode. 
PRE-PRINT (initial submitted article).

Accepted version (Elsevier, DRM2020): https://doi.org/10.1016/i.diamond.2020.108154

This estimation is done by using equation (1), where $T_{j}, T_{a m b}$ and l load are respectively the desired device junction temperature in steady state operation, the ambient temperature (300 K) and the power converter load current (10 A). Only the conduction losses are taken into account in a first step, an estimation of the switching losses will be further presented. A difference can be seen by comparing the design of the thermal resistance for the two semiconductor materials. By using the diamond semiconductor, the design of the heatsink thermal resistance is of great interest to reduce the semiconductor losses. Indeed, the thermal resistance has to be high enough to allow the diamond device to increase its temperature thanks to a self-heating effect. This method has to be used to reduce the device on-state resistance. This assessment is not the same for SiC materials where the losses are minimized at room temperature. In that case, the thermal resistance has to be minimized if the objective is the limitation of the semiconductor losses.

$$
R_{t h}=\frac{T_{j}-T_{a m b}}{R_{O N} \times{I_{l o a d}}^{2} \times(1-\alpha)}
$$

For the following comparisons, several conditions are considered. Concerning the temperature, high temperature power modules have been already demonstrated with a maximum operating temperature between $475 \mathrm{~K}$ and $525 \mathrm{~K}$ [32]-[34]. We then assume in this study that the maximum operating junction temperature allowed by the power modules for diamond and SiC diodes is $450 \mathrm{~K}$. Moreover, the following hypotheses have been used:

- $\quad$ The surface of the diamond Schottky diode is sized by three methods, the performances of these designs are then compared. The selected areas are compared in Figure 5. 


\section{$\begin{array}{lll}3.92 \mathrm{~mm}^{2} & 3.11 \mathrm{~mm}^{2} \quad 1.77 \mathrm{~mm}^{2} \quad 3.92 \mathrm{~mm}^{2}\end{array}$}

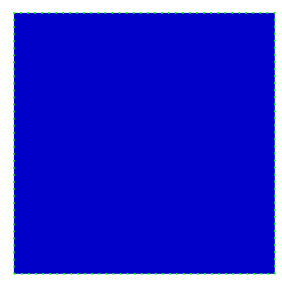

$\mathrm{SiC}$

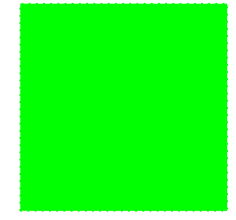

Diam.

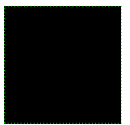

Diam.

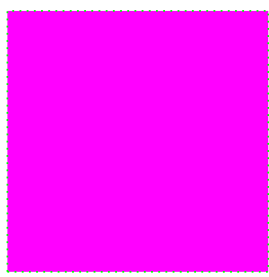

Diam.

Case 3

Figure 5: Size of the selected dies for the performance comparison. The SiC die is extracted from the diode's datasheet, sizes of the diamond die are designed for the different detailed cases. Drawn to scale.

Case 1. The diamond diode conduction loss density at $300 \mathrm{~K}$ is the same as the one of the $\mathrm{SiC}$ diode at $300 \mathrm{~K}\left(73 \mathrm{~W} / \mathrm{cm}^{2}\right)$.

Case 2. The diamond diode conduction loss density at $450 \mathrm{~K}$ is the same as the one of the $\mathrm{SiC}$ diode at $300 \mathrm{~K}$.

Case 3. The diamond diode surface is equal to the SiC diode surface $\left(3.92 \mathrm{~mm}^{2}\right)$.

- The semiconductor losses $\left(P_{\text {tot }}\right)$ are the sum of the conduction losses ( $\left.P_{\text {cond }}\right)$ and the switching losses $\left(P_{s w}\right)$. $P_{\text {cond }}$ is calculated using equation $(2)$, where $R_{o N}$ is the on-state resistance of the diode at a given temperature (T) and $\mathrm{l}_{\text {load }}$ is the load current of the buck converter equal to $10 \mathrm{~A}$.

$$
P_{\text {cond }}(T)=R_{O N}(T) \times I_{\text {load }}^{2} \times(1-\alpha)
$$


PRE-PRINT (initial submitted article).

Accepted version (Elsevier, DRM2020): https://doi.org/10.1016/j.diamond.2020.108154

- The transistor associated to the Schottky diode determines the switching losses. We assume that for a diode and a well-designed transistor, the output capacitance of the transistor (Coss) is equal to the transition capacitance of the Schottky diode $\left(\mathrm{C}_{\mathrm{T}}\right)$. To include the impact of the Schottky diode in the switching losses, the hypothesis that $C_{T}$ is added to $C_{0 s s}$ is used to calculate $\mathrm{P}_{\mathrm{sw}}$; the sum of these two capacitances is named $\mathrm{C}_{\mathrm{sw}}$. We also consider that the charge and discharge of the input capacitance of the transistor $\left(C_{\mid S S}\right)$ is fast compared to the hard switching of the power voltage and current. Hence the gate driver circuit is neglected and has no impact on the switching losses. These hypotheses lead to the lowest possible switching losses values, which would be further increased considering circuit parasitics and EMI-induced limitations [35], [36]. The switching losses $P_{s w}$ are determined by the switching frequency and the energy dissipated during the transistor turn-on $\left(\mathrm{P}_{\mathrm{t} . \text { on }}\right)$ and turn-off $\left(\mathrm{P}_{\mathrm{t} \text {.off }}\right)$. They are calculated as follows:

1. For $\mathrm{P}_{\mathrm{t} . o n}$, we consider that the charges stored in $\mathrm{C}_{\mathrm{sw}}$ are dissipated in the transistor's channel. By considering both transistor and diode with a NPT design, the non-linearity of the transistor's output capacitance and the diode transition capacitance can be estimated by equation (3) [37]. $C_{0 s s(V)}, C_{T(V)}, C_{T(1000 V)}$ and $V$ are respectively the output capacitance of the transistor at a given voltage, the diode transition capacitance at a given voltage, the transition capacitance of the diode at $900 \mathrm{~V}$ and the voltage across the semiconductor device. For the SiC Schottky diode, $\mathrm{C}_{\mathrm{T}(900 \mathrm{~V})}$ is determined by its datasheet, whereas for the diamond SBD it is calculated from equation (4), where $\varepsilon_{0}, \varepsilon_{r}, S_{\text {diode }}$ and ep $p_{p}$-are respectively the vacuum permittivity, the diamond relative permittivity (5.7), the diamond diode 
PRE-PRINT (initial submitted article).

Accepted version (Elsevier, DRM2020): https://doi.org/10.1016/j.diamond.2020.108154

surface and the diamond drift layer thickness. Based on these equations, $\mathrm{P}_{\mathrm{t} . \mathrm{on}}$ is calculated by using equation (5), $\mathrm{V}_{\text {bus }}$ being the buck converter nominal voltage.

$$
\begin{gathered}
C_{O S S(V)}=C_{T(V)}=C_{T(900 \mathrm{~V})} \sqrt{\frac{900}{V}} \\
C_{T(900 \mathrm{~V})}=\epsilon_{0} \times \epsilon_{r} \times \frac{S_{\text {diode }}}{e p_{p^{-}}} \\
P_{\text {t.on }}=\frac{2}{3} \times C_{T(900 \mathrm{~V})} \times V_{\text {bus }}^{2} \times f_{\text {sw }}
\end{gathered}
$$

2. For $\mathrm{P}_{\mathrm{t} . \text { off }}$ by assuming a fast discharge of $\mathrm{C}_{\mathrm{ISS}}$, we can consider that the transistor channel is opened rapidly. Once the channel is opened, the crossover between the power voltage and current during the turn-off is due to a charge of $C_{s w}$. In this special case, the energy is stored in $\mathrm{C}_{\text {sw }}$ and is not to be dissipated. This hypothesis has been considered in this study, the switching losses are then only due to the transistor's turn-on.

- $\quad$ The volume of the heatsink is estimated for a given operating (steady state) junction temperature and the calculated total semiconductor losses. A natural convection is assumed in this study and we consider that the thermal resistance is only caused by the heatsink. The heatsink volume is finally estimated by equation (6), with the hypothesis that a typical volume thermal resistance is between $500 \mathrm{~cm}^{3} . \mathrm{K} / \mathrm{W}$ and $800 \mathrm{~cm}^{3} . \mathrm{K} / \mathrm{W}$ [38]. This estimated volume is used as a guide to compare volumes required for diamond and SiC semiconductors. Even if the volume of heatsinks can vary with a lot of parameters like the shape of the heatsink, its material, the altitude... this estimated value allows a comparison between diamond and SiC semiconductors for the same application, with similar hypotheses and realistic data. 
PRE-PRINT (initial submitted article).

Accepted version (Elsevier, DRM2020): https://doi.org/10.1016/j.diamond.2020.108154

$$
\frac{500}{R_{t h}}<\text { heatsink volume }<\frac{800}{R_{t h}}
$$

\section{BENCHMARK RESULTS}

Evolutions of the heatsink volume and total losses of both semiconductors as a function of the junction temperature are presented in Figure 6 and Figure 7. For readability reasons, only the mean value of the range of volume values calculated from equation (6) are shown. For all diodes, the increase of the operating temperature allows a decrease of the heatsink volume. However, as regards to the total losses evolution, the analysis is different. By increasing the junction temperature from $300 \mathrm{~K}$ to $450 \mathrm{~K}$, the total losses of the SiC Schottky diode are almost doubled (multiplied by 1.9). This assessment is different for the diamond SBD where the total losses are decreased with the increase of temperature. 
PRE-PRINT (initial submitted article).

Accepted version (Elsevier, DRM2020): https://doi.org/10.1016/i.diamond.2020.108154

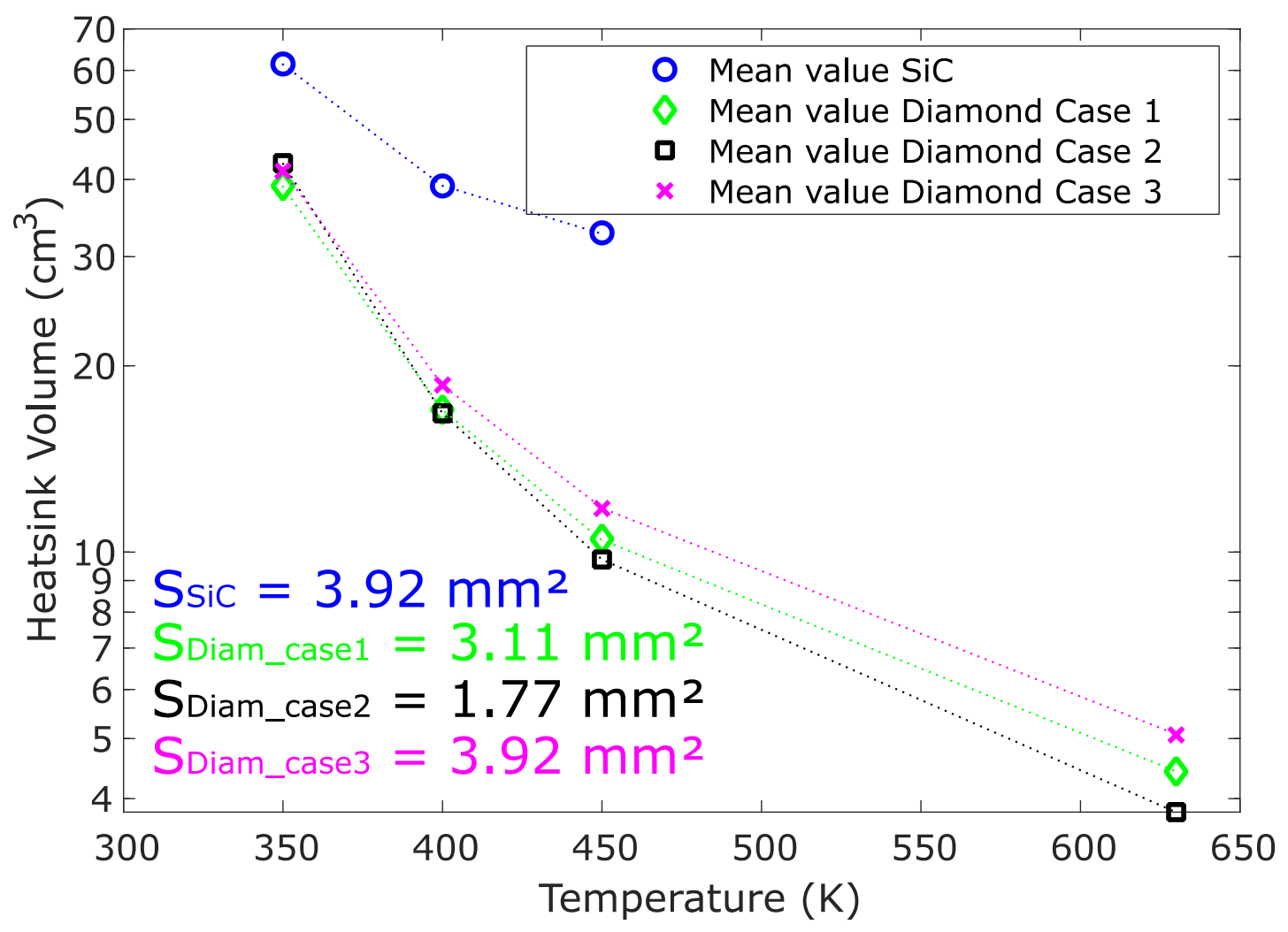

Figure 6: Estimated heatsink volume for the SiC and diamond Schottky diodes as a function of the junction temperature, corresponding to the converter operating point and hypotheses $\left(f_{s w}=25\right.$ $\mathrm{kHz}$. The volumes for the three surfaces of the diamond SBD are compared. 
PRE-PRINT (initial submitted article).

Accepted version (Elsevier, DRM2020): https://doi.org/10.1016/j.diamond.2020.108154

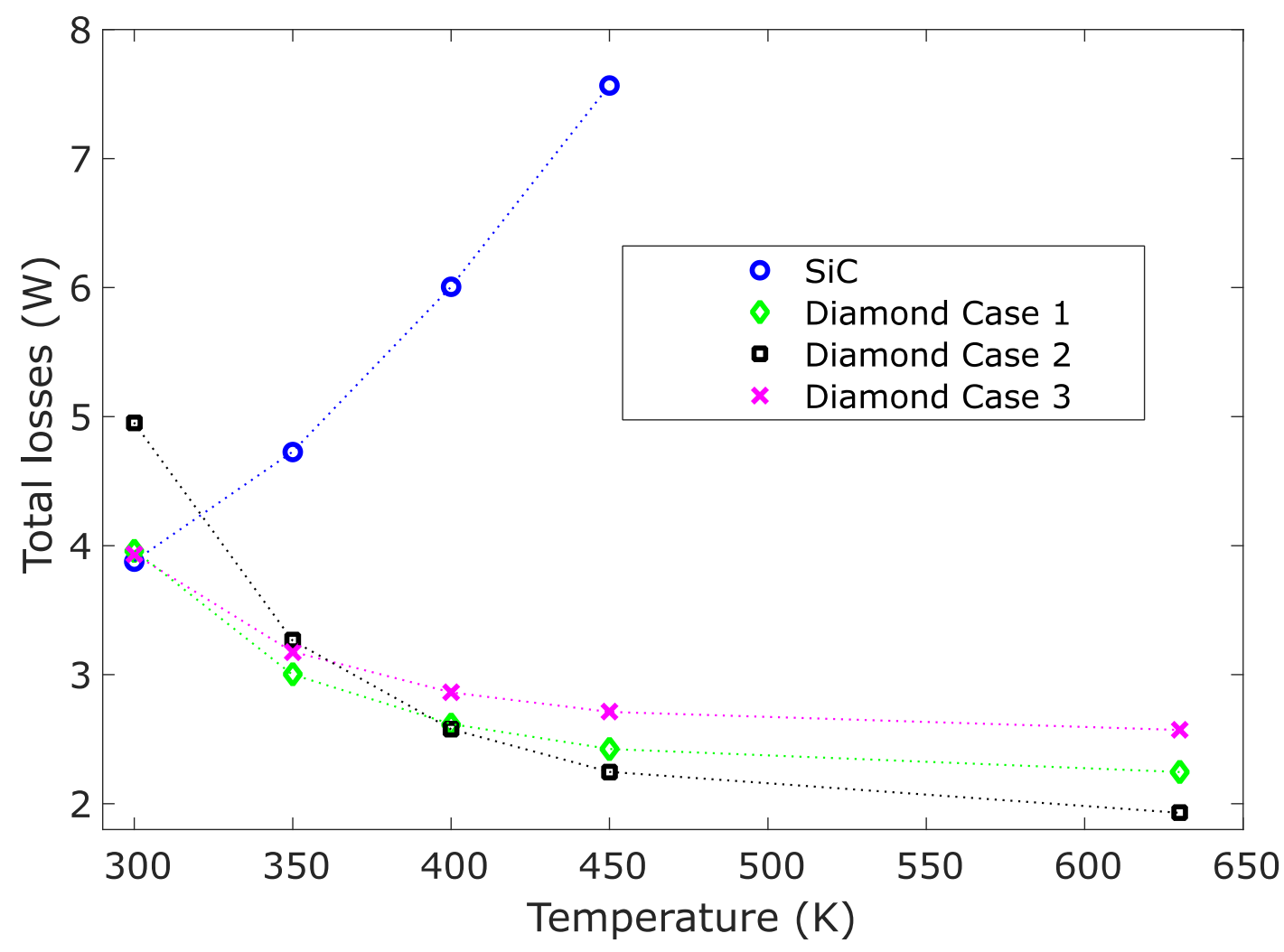

Figure 7: Estimated total losses of the SiC and diamond Schottky diodes as a function of the junction temperature $\left(\mathrm{f}_{\mathrm{sw}}=25 \mathrm{kHz}\right)$.

For a diamond surface designed by the conduction losses density at $450 \mathrm{~K}$ (black squares), an operation at $450 \mathrm{~K}$ allows to divide by a factor of two the total losses of the diode in comparison to an operation at $300 \mathrm{~K}$. The main difference between SiC and diamond components in power electronics applications is that by using SiC devices there is a tradeoff between the decrease of the converter volume (heatsink volume) and the increase of the semiconductor losses for an increase of the operating temperature. By using diamond semiconductors, increasing the operating temperature allows both the decrease of the converter volume and the semiconductor losses. Increasing the junction temperature is then of high interest for diamond power devices. 
PRE-PRINT (initial submitted article).

Accepted version (Elsevier, DRM2020): https://doi.org/10.1016/j.diamond.2020.108154

This is particularly interesting relatively to the targeted junction temperatures which are high but realistic for the realization of high temperature power modules [32]-[34]. However, increasing the junction temperature higher than $450 \mathrm{~K}$ for diamond devices has not so much interest, even for low breakdown voltages in the $\mathrm{kV}$ range. A decrease of the heatsink volume is noticed but the total losses are only lightly improved. Moreover, the realization of power modules for temperatures higher than $525 \mathrm{~K}$ is very challenging, even if the most suitable materials for high temperature packaging have been identified [39], [40]. From these analyses, diamond semiconductors can be very interesting for the realization of high performance power converters. For a $450 \mathrm{~K}$ operation, they allow to divide by three both heatsink volume and total semiconductor losses in comparison to SiC semiconductors for the same application. Both the efficiency and the converter power density can be increased by using diamond semiconductors.

Concerning the impact of the surface on the diamond Schottky diode performance, Erreur! Source du renvoi introuvable. shows the evolution of the conduction and switching losses as a function of the diode surface at a $450 \mathrm{~K}$ junction temperature. For a given application $\left(V_{\text {bus, }}, l_{\text {load }}, f_{s w}\right)$, one can see that the total losses are minimized for the diode surface allowing an equality between the conduction and switching losses. For small diode surfaces, total losses are dominated by conduction due to the higher diode on-state resistance. For large diode surfaces, the transition capacitance of the diode is increased, increasing the switching losses. The three diamond diode surfaces previously designed are compared in this graph, which explains the differences between the volumes and the total losses previously estimated. The diamond diode surface sized at $1.77 \mathrm{~mm}^{2}$ by comparing the power density at $450 \mathrm{~K}$ for diamond and at $300 \mathrm{~K}$ for 
PRE-PRINT (initial submitted article).

Accepted version (Elsevier, DRM2020): https://doi.org/10.1016/j.diamond.2020.108154

SiC (Case 2), has lower losses and heatsink volume because of its closest surface to the optimized one for this temperature $\left(2 \mathrm{~mm}^{2}\right)$.

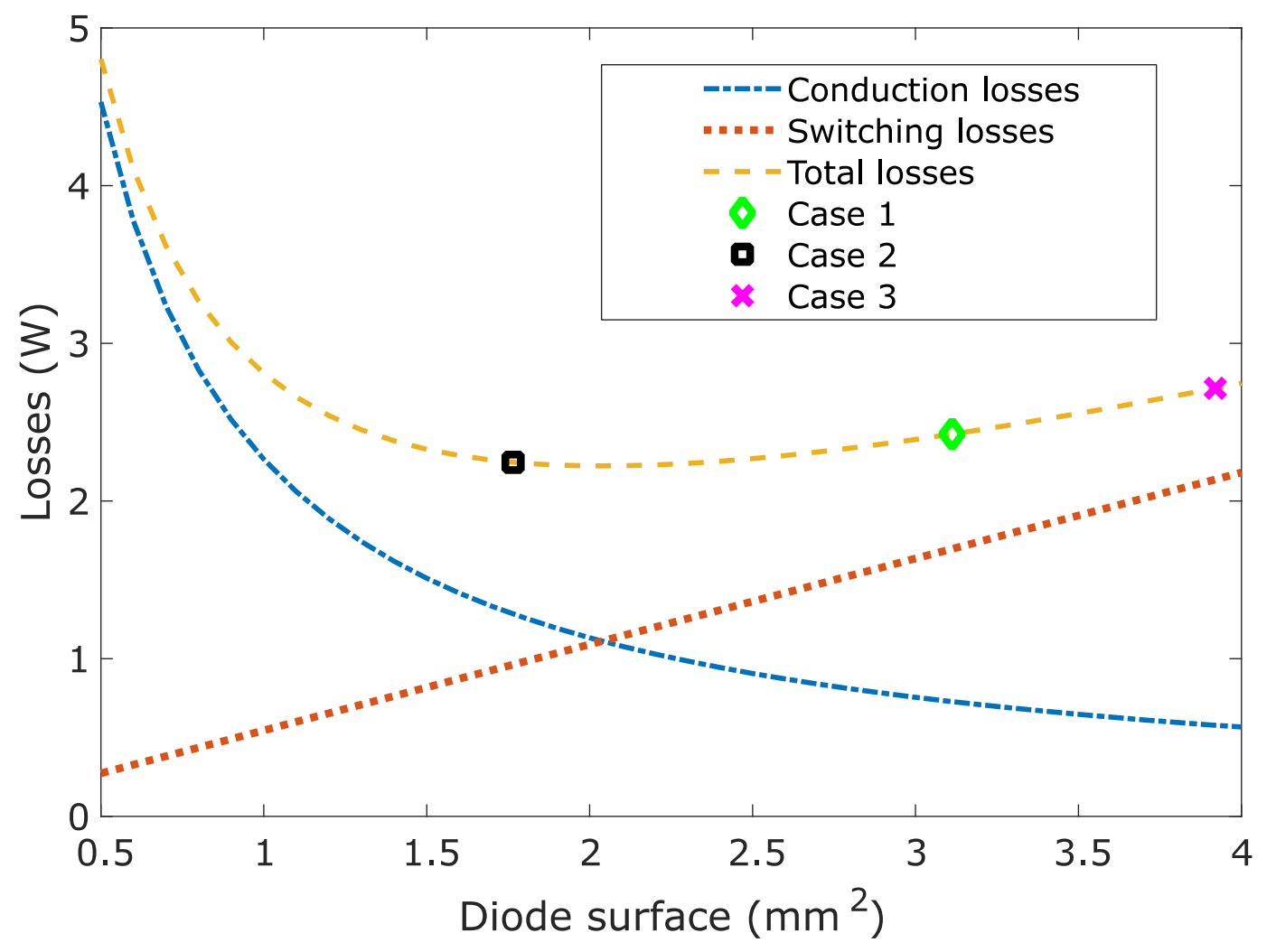

Figure 8: Detail of the conduction and switching losses of the diamond Schottky diode at $450 \mathrm{~K}$ as a function of the diode surface ( $\mathrm{fsw}=25 \mathrm{kHz}$ ). The three diode surfaces previously designed are compared.

Figure 8 compares the heatsink volumes and total losses of each diode normalized to those of SiC. It shows that both heatsink volume and diode losses are divided by a factor of three (at $450 \mathrm{~K}$ ) by using a $1.77 \mathrm{~mm}^{2}$ diamond diode (Case 2) instead of SiC. These benefits are decreased if the diamond surface is sized at $0.0392 \mathrm{~cm}^{2}$, the volume and losses are "only" divided 
PRE-PRINT (initial submitted article).

Accepted version (Elsevier, DRM2020): https://doi.org/10.1016/j.diamond.2020.108154

by 2.5 . The diamond diode surface is then an important parameter to optimize the losses for a given application.

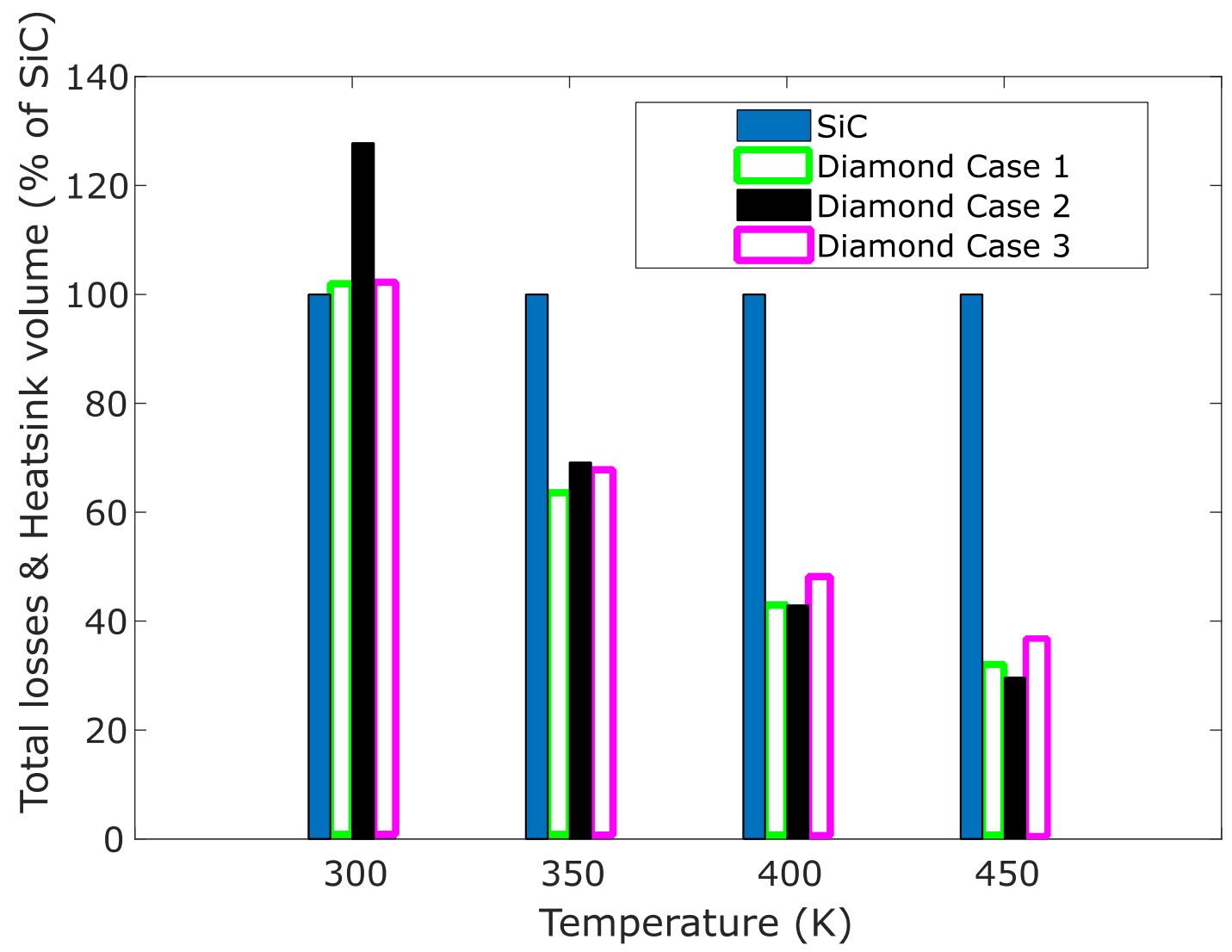

Figure 8: Total losses and heatsink volume of SiC Schottky diode and the three surfaces of diamond SBD as a function of the temperature; the values are normalized with the performances of the SiC diode at each temperature.

However this estimation is not a singularity of diamond semiconductors, this assessment is true for the others semiconductor materials. Nevertheless, benefits offered by diamond components at high temperature are lowered for low temperature operations. The estimated 
PRE-PRINT (initial submitted article).

Accepted version (Elsevier, DRM2020): https://doi.org/10.1016/j.diamond.2020.108154

losses at ambient temperature show that even for an optimized diamond SBD at $300 \mathrm{~K}$ (Case 1), the diamond losses are higher than those of SiC diode. Finally, by comparing losses and volume of both $\mathrm{SiC}$ and diamond diodes at their optimized temperature, losses of SiC diode at $300 \mathrm{~K}$ (3.9 W) are higher than those of diamond diode at $450 \mathrm{~K}(2.2 \mathrm{~W}$ for Case 2$)$. It highlights the benefits that diamond semiconductors could bring in power electronics applications.

Another advantage allowed by diamond and wide bandgap semiconductors is the increase of the switching frequency, leading to smaller and lighter passive elements [41]. Figure 9 shows the estimated heatsink volume and semiconductors total losses of SiC and Diamond as a function of the temperature. The best diamond design at $450 \mathrm{~K}$ (Case 2) has been selected. For this comparison, the diamond switching frequency has been increased at $125 \mathrm{kHz}$, whereas reduced five times with $\mathrm{SiC}$ devices $(25 \mathrm{kHz})$. It is shown that for a $450 \mathrm{~K}$ operation, diamond semiconductor losses $(6.1 \mathrm{~W})$ are still lower than the SiC losses (7.6 W) even with the increase of the switching frequency. This gain in semiconductor losses and heatsink volume $\left(26.4 \mathrm{~cm}^{3}\right.$ for diamond and $32.8 \mathrm{~cm}^{3}$ for $\mathrm{SiC}$ ) are associated to a decrease of the power converter input filter due to the increase of the switching frequency. Indeed, as shown in [42], the volume of power converter's input filter is decreased with the increase of the switching frequency. The power converter efficiency and its power density are also improved by using diamond converter at higher switching frequency, showing another advantage allowed by diamond semiconductors. 
PRE-PRINT (initial submitted article).

Accepted version (Elsevier, DRM2020): https://doi.org/10.1016/j.diamond.2020.108154

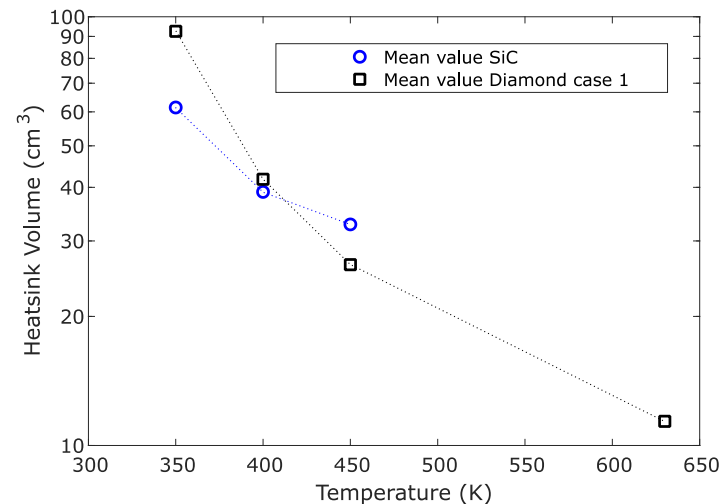

a)

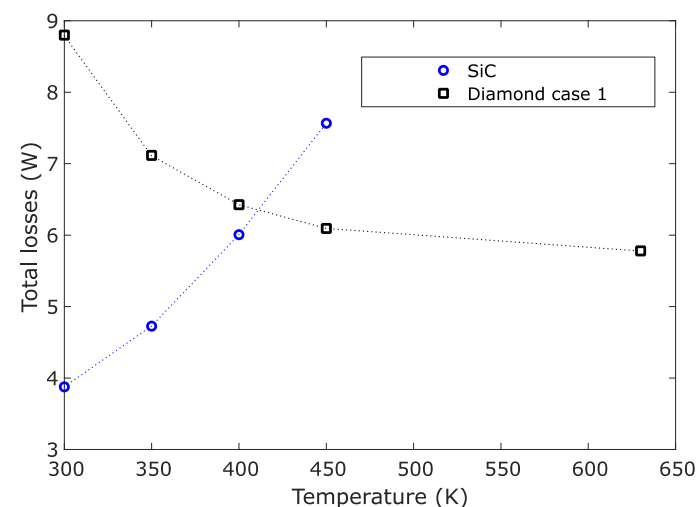

b)

Figure 9: a) Estimated heatsink volume and b) estimated total losses of the SiC diode and the best diamond design at $450 \mathrm{~K}$. The diamond switching frequency is set at $125 \mathrm{kHz}$, five times the one of $\mathrm{SiC}(25 \mathrm{kHz})$.

To highlight the improvement of diamond performances at high temperatures and to confirm the hypotheses of the benchmark presented in section II, practical test results with diamond devices are mandatory. For this purpose, the diamond diode device shown previously was integrated in a buck converter as presented in Figure 10. The diamond device is assembled on an alumina substrate $\left(\mathrm{Al}_{2} \mathrm{O}_{3}\right)$ by using $25 \mu \mathrm{m}$ wire bondings. This package is then plugged on the power converter, and this solution allows to apply a heating source on the back side of the alumina substrate. The diamond device temperature can then be controlled by keeping the entire converter at Room Temperature. A double pulse test is considered in this study, allowing lower semiconductor self-heating effect than a steady state operation. The diamond junction temperature is then controlled by the heating source, where the maximum temperature is limited to $450 \mathrm{~K}$. The diamond diode is associated with a Si MOSFET (BSS87 from Infineon corporation), 
PRE-PRINT (initial submitted article).

Accepted version (Elsevier, DRM2020): https://doi.org/10.1016/j.diamond.2020.108154

which is selected to match the diamond diode characteristics (breakdown voltage and parasitic capacitance). Due to a combination of a low current level and fast switching, the semiconductors switched currents were not measured. The comparisons have then been compared with voltage measurements.

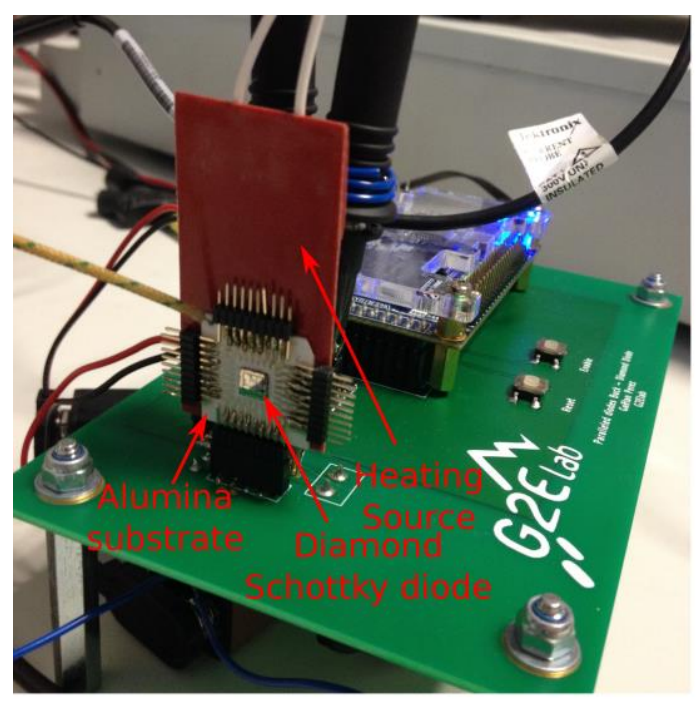

a)

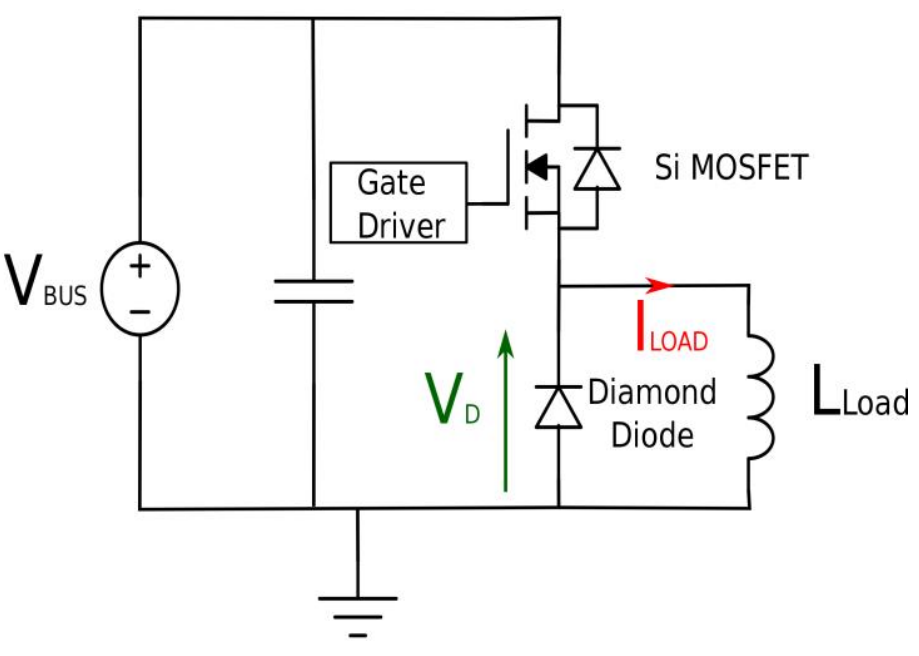

b)

Figure 10: a) Picture of the realized buck converter with the integrated diamond Schottky diode for the double pulse test, b) Schematic of the buck converter.

Figure 11 shows the diode voltage variation $\left(d V_{D} / d t\right)$ during the diode turn-on and turnoff for $50 \mathrm{~V} / 200 \mathrm{~mA}$ at three temperatures, highlighting that the temperature has no impact on the diode switching behavior. This is mainly due to the parasitic capacitor of the diamond SBD, which is not affected by the temperature. Figure 13 represents the experimental C-V measurement of the diamond Schottky diode, which is not influenced by the temperature. Figures 12 and 13 clearly show that the switching losses of diamond SBD are temperature independent. 
PRE-PRINT (initial submitted article).

Accepted version (Elsevier, DRM2020): https://doi.org/10.1016/j.diamond.2020.108154

The theoretical analysis demonstrates that the switching losses are not impacted by the temperature.

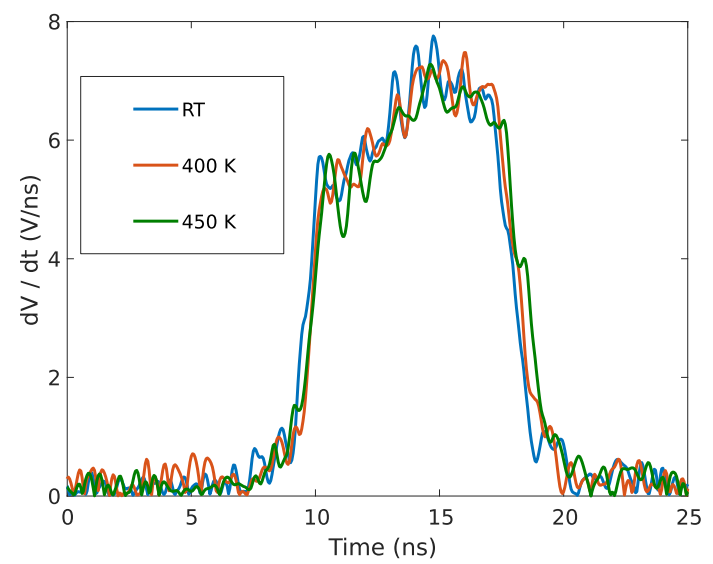

a)

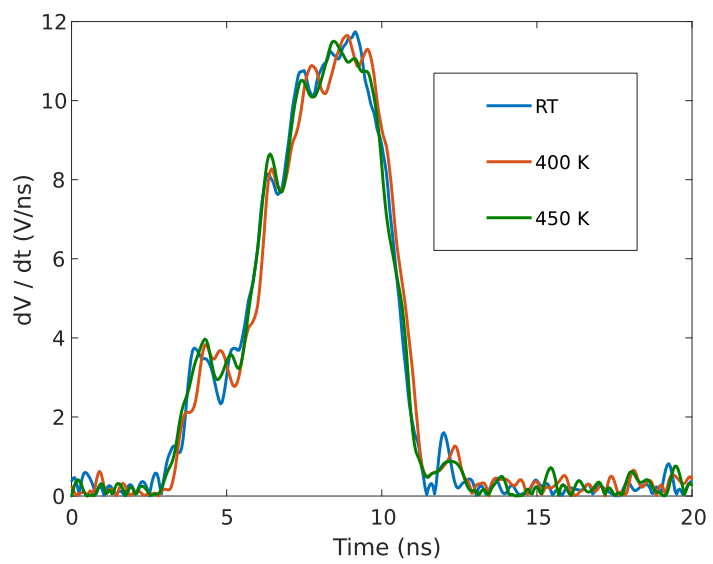

b)

Figure 11: Measured diode voltage $\left(V_{D}\right)$ derivative as a function of time, for different temperatures (double pulse test at $50 \mathrm{~V} / 200 \mathrm{~mA}$ corresponding to a $500 \mathrm{~A} / \mathrm{cm}^{2}$ current density). a) Diode turn-on (transistor turn-off), b) Diode turn-off (transistor turn-on)

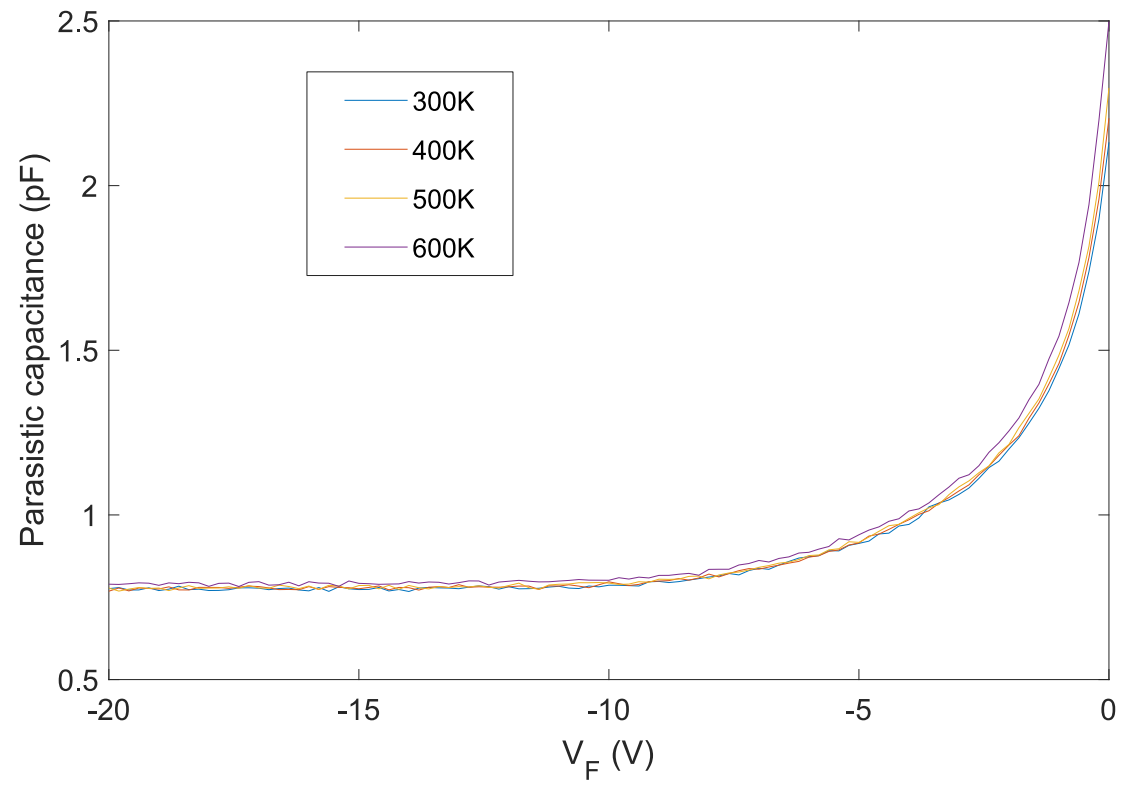


PRE-PRINT (initial submitted article).

Accepted version (Elsevier, DRM2020): https://doi.org/10.1016/j.diamond.2020.108154

Figure 12: Small signal AC measurement of the Diamond Schottky diode parasitic capacitor (device area is $200 \mu \mathrm{m} \times 200 \mu \mathrm{m}$ ). The small signal amplitude was $30 \mathrm{mV}$ and the small signal frequency $1 \mathrm{MHz}$.

Figure 13a) presents the diode voltage and the load current for the double pulse test at room temperature. A zoom on $V_{D}$ during the diode conduction is also presented in Figure 13b), showing the modification of the diode voltage drop for the same load current at different temperatures. The diode voltage drop is decreased with the increase of temperature, leading to a decrease of the diamond diode conduction losses at high temperature. The constant switching losses combined with the decrease of conduction losses for an increase of temperature lead to an improvement of the diamond diode total losses at high temperature. This highlights the theoretical estimations previously realized.

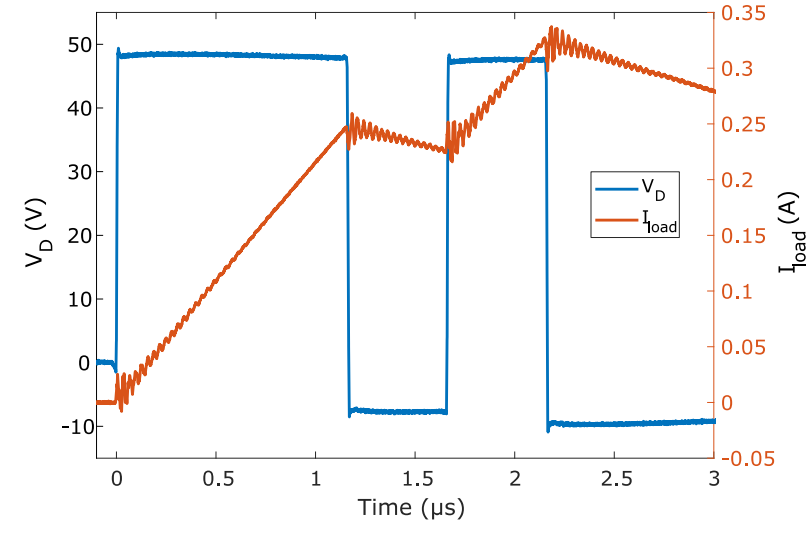

a)

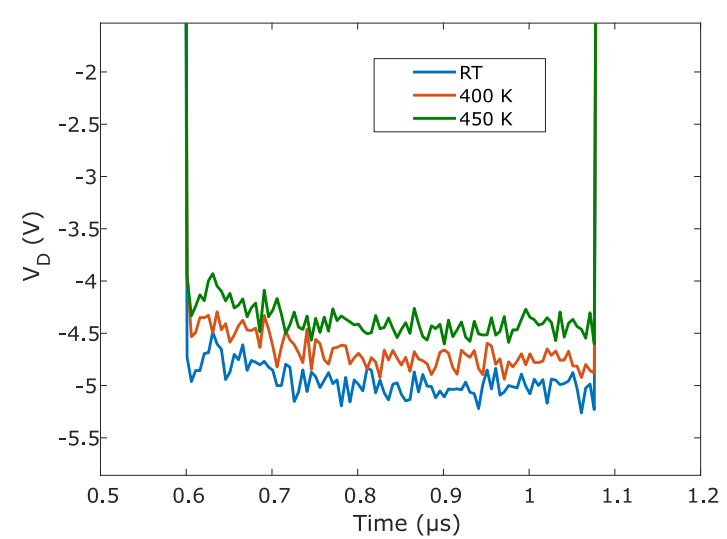

b)

Figure 13: a) Diode voltage and load current for a double pulse test at $50 \mathrm{~V} / 200 \mathrm{~mA}\left(500 \mathrm{~A} / \mathrm{cm}^{2}\right)$ at room temperature, b) Zoom on the diamond diode on-state voltage drop as a function of the temperature. 
PRE-PRINT (initial submitted article).

Accepted version (Elsevier, DRM2020): https://doi.org/10.1016/j.diamond.2020.108154

Finally, the impact of the power converter design on the diode losses is analyzed. Only the modeled diamond diode with a $1.77 \mathrm{~mm}^{2}$ surface (best design at $450 \mathrm{~K}$ ) is compared to the SiC diode. The thermal resistance associated to each diode heatsink (65 K/W for diamond and 19.2 $\mathrm{K} / \mathrm{W}$ for $\mathrm{SiC}$ ) is determined to allow a $450 \mathrm{~K}$ operation at $10 \mathrm{~A}$ and is kept constant. The evolution of diodes performances as a function of the load current is presented in Figure 14.

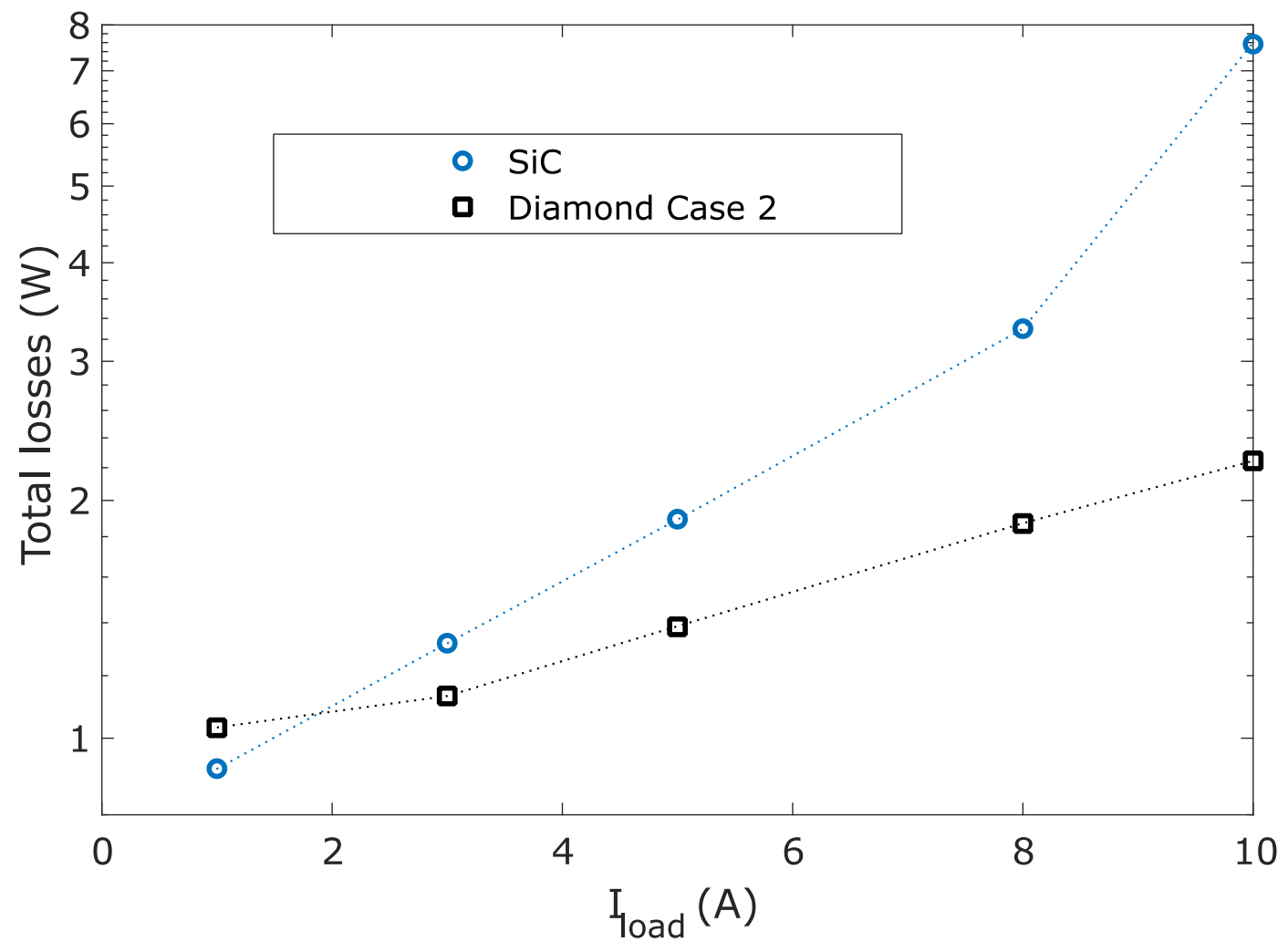

Figure 14: Comparison of the total losses of a diamond and SiC Schottky diode as a function of the load current, for the same switching frequency $(25 \mathrm{kHz})$. The diode heatsink is kept constant for all the load currents, Diamond one is three times smaller than the SiC one. The junction temperature for both diamond and SiC devices is $450 \mathrm{~K}$ at $10 \mathrm{~A}$. 
PRE-PRINT (initial submitted article).

Accepted version (Elsevier, DRM2020): https://doi.org/10.1016/j.diamond.2020.108154

It simulates the integration of semiconductors devices in a power converter where the operating conditions are modified. It can also present a case where both diodes and power modules are oversized regarding to the power converter nominal current. Results show that advantages allowed by diamond at $10 \mathrm{~A}$ are decreased for lower load currents. Moreover, losses of the diamond diode are even higher than SiC diode for very low currents ( $1 \mathrm{~A}$ for this example, $10 \%$ of the rated current). This evolution is explained by the modification of the self-heating effect on diodes due to the modification of the load current, and the higher on-state resistance of diamond at lower temperatures. For diamond, the low currents do not sufficiently increase the device junction temperature to reduce its on-state resistance; the interest of diamond is then decreased. It shows that to be interesting compared to SiC power devices, diamond semiconductors have to operate at higher temperatures (relatively to room temperature). Even if the targeted temperatures are reasonable for power electronics applications, the self-heating phenomenon of diamond devices needs to be sufficient. However, this temperature increase has to be controlled to avoid thermal runaway of the devices temperature and to avoid power converter and semiconductor power modules damages. This is also particularly the case during overcurrent events, where a specific attention must be paid to Schottky diode operations. The temperature management of diamond devices is then of great interest in power converters.

\section{DISCUSSION}

Such a precise temperature management by using diamond semiconductors is more sensitive than power converters made of "usual" devices such as Si, SiC or GaN. Indeed, 
PRE-PRINT (initial submitted article).

Accepted version (Elsevier, DRM2020): https://doi.org/10.1016/j.diamond.2020.108154

considering these devices, the semiconductor losses will be decreased in the case of oversized heatsinks due to the positive temperature coefficient of their on-state resistance, unlike diamond semiconductors. Then, several solutions can be used to allow diamond devices to operate at their best performances. First, the power converter can operate in a confine enclosure where the high ambient temperature is regulated to use diamond semiconductors at the targeted temperature, considering that there is no temperature exchange between the inside and outside of the enclosure. This solution has not been analyzed in this article, where the entire power converter (gate drivers, passive components ...) has to be able to operate at high temperature. The second solution is more traditional, where the environment of the power converter imposes the ambient temperature. This ambient temperature can be high or low depending on the application, but is not regulated. This is the solution analyzed in this article where the ambient temperature is imposed at $300 \mathrm{~K}$, as an arbitrary example for this case study. With this solution, a cooling system has to be defined to control the junction temperature of diamond semiconductors. In this study the cooling system is a heatsink in natural convection which is designed to allow a targeted junction temperature for given operating conditions of the power converter. However, if the operating conditions are modified, this solution does not allow to regulate the junction temperature of the diamond device. To solve this lack of temperature management flexibility, a forced flow can be added to the heatsink where the flow velocity is regulated as a function of the instantaneous device junction temperature. A high flow velocity can be used when the power converter is operated at high currents, avoiding a thermal runaway of the diamond semiconductor devices. The flow velocity can then be decreased for lower currents to allow a sufficient device self-heating effect, allowing the decrease of diamond devices on-state 
PRE-PRINT (initial submitted article).

Accepted version (Elsevier, DRM2020): https://doi.org/10.1016/j.diamond.2020.108154

resistance. Such a closed loop forced convection control can be possible by using a junction temperature estimation of the device in operation in the power converter [43]. This solution can be analyzed with a particular care on the dynamic response of the temperature control loop to avoid the diamond device thermal runaway.

Considering the diamond devices, further works are still required to bring such attractive devices in power converters. The first main improvements are the developments of devices with larger areas, with the reduction of defect densities and perfect control of diamond surface quality over a wide area. The increase of diamond "wafer" size is desired and expected [44] but even with $5 \mathrm{~mm} \times 5 \mathrm{~mm}$ diamond substrates, there is a possibility to fabricate in a first development step diamond devices with current ratings higher than 100A. Moreover, some studies are done on heteroepitaxially grown diamond substrates [45]. The parallelization of diamond devices, considering both the NTC and PTC coefficients and the use of higher thermal resistances must be investigated. A first step towards parallelization of diamond devices has been presented in [46]. The second improvements on the diamond devices are the required solutions to increase the electric field during the off-state. Indeed, reaching higher electric field, closer to the theoretical 1D breakdown, will help to increase the doping level of the drift layer and therefore reducing even further the on-state losses. Innovative solutions have been proposed for diamond junction terminations [47]-[49], which must be further investigated and fabricated.

The theoretical benchmark proposed here must be confirmed by a fair comparison between power converters with the same specifications. Since SiC power devices are well suited for $600 \mathrm{~V}-1 \mathrm{kV}$ voltage ranges, current ratings above $10 \mathrm{~A}$ and high switching frequencies (>20 
PRE-PRINT (initial submitted article).

Accepted version (Elsevier, DRM2020): https://doi.org/10.1016/j.diamond.2020.108154

$\mathrm{kHz}$ ), similar diamond devices must be fabricated. Unfortunately, many diamond devices available at the moment suffer from premature breakdown voltage and/or high defect density reducing the maximum total active area. Consequently, it is quite difficult to integrate diamond devices in a $600 \mathrm{~V}-1 \mathrm{kV}, 10 \mathrm{~A}$ class power converter, to be further benchmarked with SiC-based power converters. However, we report here the fastest switching of a power converter with diamond devices ( 8 to $12 \mathrm{~V} / \mathrm{ns}$, Figure 12 ). We also demonstrate here experimentally that diamond devices will switch at the same speed when operating at high temperature (see Figure 12 and 14), and will have lower conduction losses at higher temperatures (see Figure 1 and 13b).

\section{CONCLUSION}

This article presents a comparison between the performances of diamond and SiC power devices in the way to highlight the benefits that diamond could bring to the power electronics community. The diamond device characteristics are based on analytical models and are compared to a commercial SiC Schottky diode. The comparisons are performed on the estimated total semiconductor losses in a $900 \mathrm{~V} / 10 \mathrm{~A}$ buck converter and the volume of the required heatsink as a function of the junction temperature in steady state operation of the converter. It is shown that by using diamond semiconductors both the heatsink volume and the power devices losses can be reduced or the switching frequency can be increased still with a smaller heatsink, allowing to increase the efficiency and the power density of converters. However, due to the incomplete ionization of diamond dopants at room temperature, the diamond devices have to operate at high temperature to overpass SiC components performances. Even if these results are based on several hypotheses, it shows that a precise design of converters and a temperature management 
PRE-PRINT (initial submitted article).

Accepted version (Elsevier, DRM2020): https://doi.org/10.1016/j.diamond.2020.108154

are needed to use full benefits of diamond semiconductors in power converters. It shows that special integration methods and special temperature managements have to be developed for the realization of future high efficiency power converters based on diamond devices.

\section{AKNOWLEDGMENT}

The research leading to these results has been performed within the GreenDiamond project (http://www.greendiamond-project.eu/) and received funding from the European Community's Horizon 2020 Program (H2020/2014-2020) under grant agreement $n^{\circ} 640947$.

This research is partially funded by French ANR Research Agency under grant ANR-16CE05-0023 \#Diamond-HVDC.

The LANEF framework (ANR-10-LABX-51-01) is acknowledged for its support with mutualized infrastructure.

\section{REFERENCES}

[1] J. Millan, P. Godignon, X. Perpina, A. Perez-Tomas, and J. Rebollo, "A Survey of Wide Bandgap Power Semiconductor Devices," IEEE Trans. Power Electron., vol. 29, no. 5, pp. 2155-2163, 2014.

[2] T. P. Chow, I. Omura, M. Higashiwaki, H. Kawarada, and V. Pala, "Smart power devices and ICs using GaAs and wide and extreme bandgap semiconductors," IEEE Trans. Electron Devices, vol. 64, no. 3, pp. 856-873, 2017.

[3] S. Fujita, "Wide-bandgap semiconductor materials: For their full bloom," Jpn. J. Appl. Phys., 
PRE-PRINT (initial submitted article).

Accepted version (Elsevier, DRM2020): https://doi.org/10.1016/j.diamond.2020.108154

vol. 54, no. 3, 2015.

[4] A. Maréchal et al., "Model implementation towards the prediction of J(V) characteristics in diamond bipolar device simulations," Diam. Relat. Mater., vol. 43, pp. 34-42, 2014.

[5] H. Kawarada et al., "Durability-enhanced two-dimensional hole gas of C-H diamond surface for complementary power inverter applications," Sci. Rep., vol. 7, no. August 2016, pp. 18, 2017.

[6] A. Daicho, T. Saito, S. Kurihara, A. Hiraiwa, and H. Kawarada, "High-reliability passivation of hydrogen-terminated diamond surface by atomic layer deposition of Al2O3," J. Appl. Phys., vol. 115, no. 22, 2014.

[7] Y. Kitabayashi et al., "Normally-Off C-H Diamond MOSFETs with Partial C-O Channel Achieving 2-kV Breakdown Voltage," IEEE Electron Device Lett., vol. 38, no. 3, pp. 363-366, 2017.

[8] J. Pernot, C. Tavares, E. Gheeraert, E. Bustarret, M. Katagiri, and S. Koizumi, "Hall electron mobility in diamond," Appl. Phys. Lett., vol. 89, no. 12, p. 122111, 2006.

[9] J. Pernot et al., "Hall hole mobility in boron-doped homoepitaxial diamond," Phys. Rev. B Condens. Matter Mater. Phys., vol. 81, no. 20, pp. 1-7, 2010.

[10] S. Tarelkin et al., "Power diamond vertical Schottky barrier diode with 10 A forward current," Phys. Status Solidi, vol. 212, no. 11, pp. 2621-2627, 2015.

[11] H. Umezawa, Y. Kato, and S.-I. Shikata, "1ohm On-Resistance Diamond Vertical-Schottky Barrier Diode Operated at 250 C," Appl. Phys. Express, vol. 6, no. 1, 2013. 
PRE-PRINT (initial submitted article).

Accepted version (Elsevier, DRM2020): https://doi.org/10.1016/j.diamond.2020.108154

[12] A. Traoré, P. Muret, A. Fiori, D. Eon, E. Gheeraert, and J. Pernot, "Zr/oxidized diamond interface for high power Schottky diodes," Appl. Phys. Lett., vol. 104, no. 5, p. 052105, 2014.

[13] H. Umezawa et al., "Leakage current analysis of diamond Schottky barrier diode by defect imaging," Appl. Phys. Lett., vol. 40, pp. 56-59, 2013.

[14] P. N. Volpe et al., "Extreme dielectric strength in boron doped homoepitaxial diamond," Appl. Phys. Lett., vol. 97, no. 22, pp. 10-13, 2010.

[15] K. Driche, H. Umezawa, N. Rouger, G. Chicot, and E. Gheeraert, "Characterization of breakdown behavior of diamond Schottky barrier diodes using impact ionization coefficients Characterization of breakdown behavior of diamond Schottky barrier diodes using impact ionization coe ffi cients," Jpn. J. Appl. Phys., 2017.

[16] H. Umezawa, M. Nagase, Y. Kato, and S. I. Shikata, "High temperature application of diamond power device," Diam. Relat. Mater., vol. 24, pp. 201-205, 2012.

[17] K. Ikeda, H. Umezawa, N. Tatsumi, K. Ramanujam, and S. ichi Shikata, "Fabrication of a field plate structure for diamond Schottky barrier diodes," Diam. Relat. Mater., vol. 18, no. 2-3, pp. 292-295, 2009.

[18] K. Driche, S. Rugen, N. Kaminski, H. Umezawa, H. Okumura, and E. Gheeraert, "Electric field distribution using floating metal guard rings edge-termination for Schottky diodes," Diam. Relat. Mater., vol. 82, no. January, pp. 160-164, 2018.

[19] Y. Jiang, W. Sung, J. Baliga, S. Wang, B. Lee, and A. Huang, "Electrical Characteristics of 10- 
PRE-PRINT (initial submitted article).

Accepted version (Elsevier, DRM2020): https://doi.org/10.1016/j.diamond.2020.108154

kV 4H-SiC MPS Rectifiers with High Schottky Barrier Height," J. Electron. Mater., vol. 3, 2017.

[20] R. A. Khadar, C. Liu, L. Zhang, P. Xiang, K. Cheng, and E. Matioli, "820-V GaN-on-Si QuasiVertical p-i-n Diodes," IEEE Electron Device Lett., vol. 39, no. 3, pp. 401-404, 2018.

[21] G. Chicot, D. Eon, and N. Rouger, "Optimal drift region for diamond power devices," Diam. Relat. Mater., vol. 69, pp. 68-73, 2016.

[22] H. Umezawa, "Recent advances in power semiconductor devices," Mater. Sci. Semicond. Process., 2018.

[23] V. S. Bormashov et al., "Thin large area vertical Schottky barrier diamond diodes with low on-resistance made by ion-beam assisted lift-off technique," Diam. Relat. Mater., vol. 75, pp. 78-84, 2017.

[24] M. Suzuki et al., "Electrical characterization of diamond PiN diodes for high voltage applications," Phys. Status Solidi, vol. 210, no. 10, pp. 2035-2039, 2013.

[25] T. Makino et al., "Diamond Schottky-pn diode without trade-off relationship between onresistance and blocking voltage," Phys. Status Solidi, vol. 207, no. 9, pp. 2105-2109, 2010.

[26] H. Umezawa, T. Matsumoto, and S.-I. Shikata, "Diamond Metal-Semiconductor Field-Effect Transistor With Breakdown Voltage Over 1.5 kV," IEEE ELECTRON DEVICE Lett., vol. 35, no. 11, 2014.

[27] T. Pham, J. Pernot, G. Perez, D. Eon, E. Gheeraert, and N. Rouger, "Deep-depletion mode boron doped monocrystalline diamond metal oxide semiconductor field effect transistor," 
PRE-PRINT (initial submitted article).

Accepted version (Elsevier, DRM2020): https://doi.org/10.1016/i.diamond.2020.108154

IEEE Electron Device Lett., vol. 38, no. 11, pp. 1571-1574, 2017.

[28] T. T. Pham et al., "Deep depletion concept for diamond MOSFET," Appl. Phys. Lett., vol. 111, no. 17, 2017.

[29] A. Hiraiwa and H. Kawarada, "Blocking characteristics of diamond junctions with a punchthrough design," J. Appl. Phys., vol. 117, no. 12, p. 124503, 2015.

[30] P.-N. Volpe, J. Pernot, P. Muret, and F. Omnès, "High hole mobility in boron doped diamond for power device applications," Appl. Phys. Lett., vol. 94, no. 9, p. 092102, 2009.

[31] X. She, A. Q. Huang, O. Lucia, and B. Ozpineci, "Review of Silicon Carbide Power Devices and Their Applications," IEEE Trans. Ind. Electron., vol. 64, no. 10, pp. 8193-8205, 2017.

[32] B. Axelrod, Y. Berkovich, and A. loinovici, "A Novel High-Temperature Planar Package for SiC," Proc. 2003 Int. Symp. Circuits Syst. 2003. ISCAS '03., vol. 3, no. 8, pp. 2059-2067, 2003.

[33] Z. Wang et al., "A high temperature silicon carbide MOSFET power module with integrated silicon-on-insulator based gate drive," 2014 IEEE Energy Convers. Congr. Expo. ECCE 2014, vol. 30, no. 3, pp. 4373-4380, 2014.

[34] Z. Chen, Y. Yao, D. Boroyevich, K. D. T. Ngo, P. Mattavelli, and K. Rajashekara, “A 1200-V, 60-A SiC MOSFET multichip phase-leg module for high-temperature, high-frequency applications," IEEE Trans. Power Electron., vol. 29, no. 5, pp. 2307-2320, 2014.

[35] T. Meade, D. O’Sullivan, R. Foley, C. Achimescu, M. Egan, and P. McCloskey, "Parasitic inductance effect on switching losses for a high frequency Dc-Dc converter," in IEEE Applied Power Electronics Conference and Exposition - APEC, 2008, pp. 3-9. 
PRE-PRINT (initial submitted article).

Accepted version (Elsevier, DRM2020): https://doi.org/10.1016/j.diamond.2020.108154

[36] D. Reusch and J. Strydom, "Understanding the Effect of PCB Layout on Circuit Performance in a High-Frequency Gallium-Nitride-Based Point of Load Converter," IEEE Trans. Power Electron., vol. 29, no. 4, pp. 2008-2015, 2014.

[37] J. W. Kolar, F. Krismer, Y. Lobsiger, J. Muhlethaler, T. Nussbaumer, and J. Minibock, "Extreme efficiency power electronics," Integr. Power Electron. Syst. (CIPS), 2012 7th Int. Conf., pp. 1-22, 2012.

[38] X. C. Tong, Advanced Materials for Thermal Management of Electronic Packaging. SpringerVerlag New York, 2011.

[39] R. Khazaka, L. Mendizabal, D. Henry, and R. Hanna, "Survey of high-temperature reliability of power electronics packaging components," IEEE Trans. Power Electron., vol. 30, no. 5, pp. 2456-2464, 2015.

[40] L. Coppola, D. Huff, F. Wang, R. Burgos, and D. Boroyevich, "Survey on high-temperature packaging materials for SiC-based power electronics modules," PESC Rec. - IEEE Annu. Power Electron. Spec. Conf., pp. 2234-2240, 2007.

[41] R. M. Burkart and J. W. Kolar, "Comparative $n-\rho-\sigma$ Pareto Optimization of Si and SiC Multilevel Dual-Active-Bridge TopologiesWith Wide Input Voltage Range," IEEE Trans. Power Electron., vol. 32, no. 7, pp. 5258-5270, 2017.

[42] S. Safari, A. Castellazzi, and P. Wheeler, "The Impact of Switching Frequency on Input Filter Design for High Power Density Matrix Converter," in IEEE Energy Conversion Congress and Exposition (ECCE), 2014, pp. 579-585. 
PRE-PRINT (initial submitted article).

Accepted version (Elsevier, DRM2020): https://doi.org/10.1016/j.diamond.2020.108154

[43] G. Perez et al., "Integrated temperature sensor with diamond Schottky diodes using a thermosensitive parameter," Diam. Relat. Mater., vol. 78, no. August, pp. 83-87, 2017.

[44] S. Shikata, "Single crystal diamond wafers for high power electronics," Diam. Relat. Mater., vol. 65 , pp. 168-175, 2016.

[45] H. Kawashima et al., "Electronic properties of diamond Schottky barrier diodes fabricated on silicon-based heteroepitaxially grown diamond substrates," Appl. Phys. Express, vol. 8, no. 104103, pp. 1-3, 2015.

[46] G. Perez, P. Lefranc, P. Jeannin, D. Eon, N. Rouger, and U. G. Alpes, "Parallel and interleaved structures for diamond Schottky diodes. Keywords Diamond Schottky diode static characteristics," in EPE ECCE Europe, 2017, pp. 1-10.

[47] H. Arbess, K. Isoird, M. Zerarka, H. Schneider, M. Locatelli, and D. Planson, “High termination efficiency using polyimide trench for high voltage diamond Schottky diode," Diam. Relat. Mater., vol. 58, pp. 149-154, 2015.

[48] K. Driche et al., "Floating Field Rings for Pseudo-Vertical Diamond Schottky Barrier Diodes," in International Conference on Solid State Devices and Materials, 2018.

[49] M. Brezeanu et al., "Termination Structures for Diamond Schottky Barrier Diodes," in International Symposium on Power Semiconductors Devices \& IC's, 2006, pp. 2-5. 
PRE-PRINT (initial submitted article).

Accepted version (Elsevier, DRM2020): https://doi.org/10.1016/j.diamond.2020.108154 